\title{
Research on Logistics Demand Forecasting and Transportation Structure of Beijing Based on Grey Prediction Model
}

\author{
Jie Zhu, Hong Zhang, Li Zhou \\ School of Information, Beijing Wuzi University, Beijing, China
}

Email address:

dr.yuwenjunxian@gmail.com (Hong Zhang)

To cite this article:

Jie Zhu, Hong Zhang, Li Zhou. Research on Logistics Demand Forecasting and Transportation Structure of Beijing Based on Grey Prediction Model. Science Journal of Applied Mathematics and Statistics. Vol. 3, No. 3, 2015, pp. 144-152. doi: 10.11648/j.sjams.20150303.17

\begin{abstract}
This paper analyzes the present situation of Beijing logistics development, starting from the total economic output, economic structure, economic location and other aspects, basic economic situation of Beijing is analyzed. From the transportation infrastructure construction present situation, the current status of development of logistics industry, logistics enterprises are analyzed in terms of status and problems of Beijing logistics development; then further analysis of Beijing logistics development environment, all of these indicate that it is very necessary for Beijing logistics demand forecast. Using the econometric model to analyze and forecast the total demand analysis of Beijing logistics, discusses the influencing factors of Beijing logistics demand, thus the construction of index system of logistics demand forecast, and selects freight, freight turnover as a quantitative index to measure the total quantity of logistics demand, using the Eviews model and the analysis, obtains the Beijing logistics demand presents the fast growth to the situation in the future five years.
\end{abstract}

Keywords: Logistics Demand Forecasting, Econometric Model, The Grey Prediction Model

\section{Introduction}

Modern logistics is the process of industrialization in the most economical and reasonable integrated service mode as well as an important part of the modern economy, with the rapid progress of modern science and technology high speed development and the world economy, the rapid development in the global scope. In general, the level of development of the logistics industry is an important symbol to measure the comprehensive economic strength of a country and region, is a national and regional economic development of the basic industries and artery. Under the background of global economic integration, how to use the strategy planning of regional logistics system, improve the service level of the regional logistics, reduce logistics costs, improve logistics investment environment, from the single enterprise logistics rationalization to regional logistics rationalization over, realize the rational development of high levels of logistics, is the inevitable requirement of the sustainable development of regional economy. Analysis on logistics demand forecasting is one of the key problems to be solved in the layout and construction of the logistics planning. Analysis of logistics demand forecast is accurate and reasonable, determines the success of logistics planning, and then influence the development speed of regional economy. Therefore, analysis of the establishment of scientific and reasonable prediction model, based on the qualitative and quantitative analysis of logistics demand forecast, on the development of regional logistics development policy, to determine the scale of logistics infrastructure, logistics analysis of the market trend, which has important significance for more sustainable and healthy development of logistics industry.

\section{Beijing Logistics Development Status and Environmental Analysis}

\subsection{The Economic Situation in Beijing Province}

From the Beijing statistical yearbook 2014: 2009-2013 GDP data as shown in figure 2-1: 


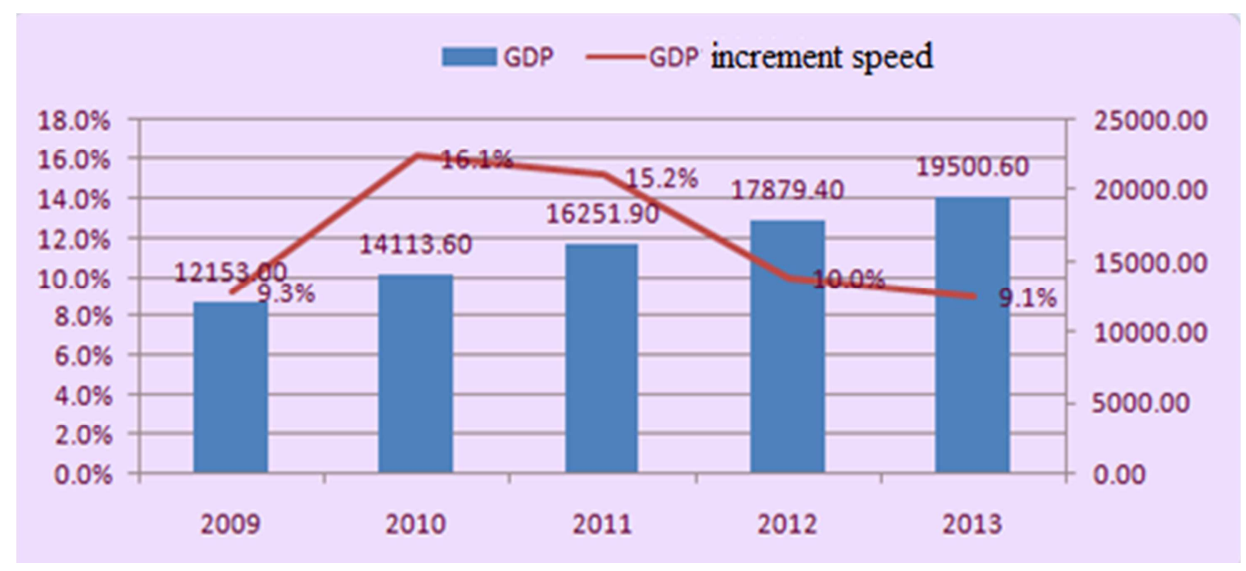

Figure 2-1. Beijing 2009-2013 GDP and growth rate.

We can be seen from figure 2-1, 2009-2013 Beijing economy maintained rapid and healthy development of the stable growth of GDP, but declining growth rate since 2010, Beijing gradually began to slow economic growth, but due to the lowest growth rate is still $9.1 \%$ of 2010 and 2011, economic growth rate above $15 \%$, shows that the quality of economic operation is still in Beijing to further improve. Due to the influence of the financial crisis in 2008 , only $9.3 \%$ growth in 2009, quick recovery reached $16.1 \%$ in 2010. 2009 gross domestic product (GDP) of \$1.2153 trillion, 2013 gross domestic product (GDP) reached 1.95006 trillion yuan, close to 2 trillion, five years to $60 \%$, suggesting that Beijing economy growth is rapid; the stability of the national economy is more and more strong.

Economic growth in 2013, in the industry, the first industry in GDP is 16.18 billion yuan, up 7.7\% from a year earlier. The second industry's GDP totaled 435.23 billion yuan, up $7.2 \%$; the tertiary industry GDP totaled 1.49865 trillion yuan, up $9.6 \%$ from a year earlier. Primary industry, secondary industry and tertiary industry GDP accounted for the proportion of GDP of $0.83 \%, 22.32 \%$ and $76.85 \%$ respectively; Primary industry, secondary industry and tertiary industry contribution rate to economic growth of $0.72 \%, 18.07 \%$ and $81.21 \%$ respectively.

In 2013, foreign economic, Beijing import and export of goods totaled $\$ 429.942$ billion, compared with $5.31 \%$ growth in 2012. Among them, the exports of $\$ 63.098$ billion, increased by $5.81 \%$, the goods imported for $\$ 366.844$ billion, increased by $5.27 \%$, imports accounted for $85 \%$ of the total amount of foreign trade, the total cost of the Beijing foreign economic is still mainly imports. 2013 new high-tech product export growth is strong; exports reached \$20.357 billion, an increase of $7.04 \%$. In 2013, the United States continue to Beijing's largest trade partner, bilateral trade value of $\$ 35.413$ billion, about $8.24 \%$ of the total cost of the Beijing import and export of the same period, of which only $\$ 5.712$ billion in exports to the United States, accounting for $16.13 \%$ of the total.

In recent years, Beijing's industry structure has stabilized small changes. Primary industry, secondary industry and tertiary industry GDP as a share of GDP in 2009 was $0.97 \%$, $23.50 \%$ and $75.53 \%, 0.83 \%, 22.32 \%$ and $0.83 \%$ in 2013 . In
2013 , the first industry in GDP as a share of GDP fell by $0.14 \%$ in January 2009, the second industry GDP as a share of GDP than in 2009 dropped by $1.18 \%$, the third industry in GDP as a share of GDP rose by $1.32 \%$ over 2009 .

In recent years, Beijing's industrial structure has the following characteristics: the first and second industry than slow down, gradually to the third industry, change is slow, explain the internal structure of Beijing's industry along with the continuous optimization have stabilised. The second industry as the basic is the relocation of shougang has left the central part of Beijing, and with the large number of foreign Banks, insurance companies, and into the travel company, the third industry has occupied the mainstream of the economy of Beijing, the first industry to economic crops also changed the past give priority to the traditional concept of crops. 2013 Beijing as a share of GDP reached $76.85 \%$, the tertiary industry's contribution to the economic growth of $81.21 \%$

In the first, in China, have decisive role on the economic development of Beijing. Transportation, postal and telecommunication services, wholesale and retail trade, finance, information, real estate, tourism, such as for Beijing's main industries, including finance, information sector is still growing momentum.

\subsection{The Beijing Logistics Development}

In Beijing in the traffic infrastructure construction investment calendar year are very big, with Beijing as the center of the highway, railway, the construction of the domestic and international air channel is very mature, is an important transportation hub in the domestic and international.

Railway, Beijing is one of the center of the rail network in China, there are mainly to the beijing-kowloon railway, Kowloon, Hong Kong and Shanghai the beijing-shanghai railway, beijing-guangzhou railway, to guangzhou to Harbin jingha railway, package to baotou Beijing railway, the original to the original Beijing railway, Beijing - guilin high-speed rail, to tgo Beijing railway and to chengde Beijing railway. In terms of international rail transport, to Russia from city to city, the north Korean capital, Pyongyang, the Mongolian capital of ulan bator, and go to the Vietnamese 
capital Hanoi train departure from Beijing. Aviation, Beijing capital international airport, is the world's largest airport in Beijing almost all domestic and international flights at Beijing capital international airport dock and take off. The passenger throughput in 2012 reached 2012 person-time, came second in the world, second only to the Atlanta airport. Road, at the end of 2013, the Beijing municipal road mileage of 21673 kilometers, an increase of $182 \mathrm{~km}$; Among them, the highway mileage of 923 kilometers, the urban road mileage of $6295 \mathrm{~km}$, an increase of 24 kilometers. In recent years, Beijing transportation of fixed assets in the fluctuating, in 2013, the district transportation investment in fixed assets of 64.45 billion yuan, reduced by $6.67 \%$ over the previous year, show that Beijing's traffic construction has been mature and stable.

Beijing social logistics total is 7.22986 trillion yuan in 2013, compared with 2012, 6.58511 trillion yuan, increased by $9.8 \%$, and the logistics business income also increased from $\$ 2012$ in 210.44 billion to 2013 of 226.76 billion yuan, increasing 7.8\%. In 2013 Beijing logistics staff 489000 people, compared with 2012 in 519000 decreased by $5.8 \%$, $5.6 \%$ of the city's tertiary industry practitioners, was down more than $0.6 \%$ in 2012 . Reduce workers, and total logistics rising, the logistics industry in Beijing is constantly optimized and the trend of rapid development.

Beijing logistics also has many problems; however, the first is the explosive growth in the number of motor vehicles, vehicle ownership in Beijing in 2013 to 5.437 million vehicles, including 4.265 million units of private cars. Second number explosive growth, while vehicles but parking facilities in Beijing have not been corresponding growth, the number of public parking space in Beijing only reached to about $15 \%$ of car ownership, and road area rate, reduce the ability of urban road microcirculation, Beijing road overall capacity is low. The last major administrative, financial, hospital, school, business, and entertainment venues and other urban public service facilities are mostly concentrated in the areas of the city, causing the city high density of population, commerce, building, this led directly to the traffic density, accounts for only $6 \%$ of the urban area within the second, but $30 \%$ of the concentration of the motor vehicle traffic in the city.

\section{Beijing Logistics Demand Forecast of Transportation Structure}

In this chapter, based on the analysis of the development of Beijing freight transportation, the calculation and analysis of various modes of transportation freight volume of Beijing, the share rate of transport turnover ratio, in order to explain the variation characteristics of Beijing logistics demand of transportation structure, using the gray forecasting model to predict the next five years Beijing various modes of transportation freight volume share, share rate trend different transportation turnover volume, the total logistics demand forecasting results of railway, highway, predict, civil aviation and pipeline in the next five years the volume of freight, cargo turnover tendency.

\subsection{Beijing Cargo Transportation Development}

Various ways of transportation in Beijing has been in a healthy and rapid development, the sustained and stable development of the transport industry.

From 2003-2013 years freight volume and freight volume changes as shown in 3-1.

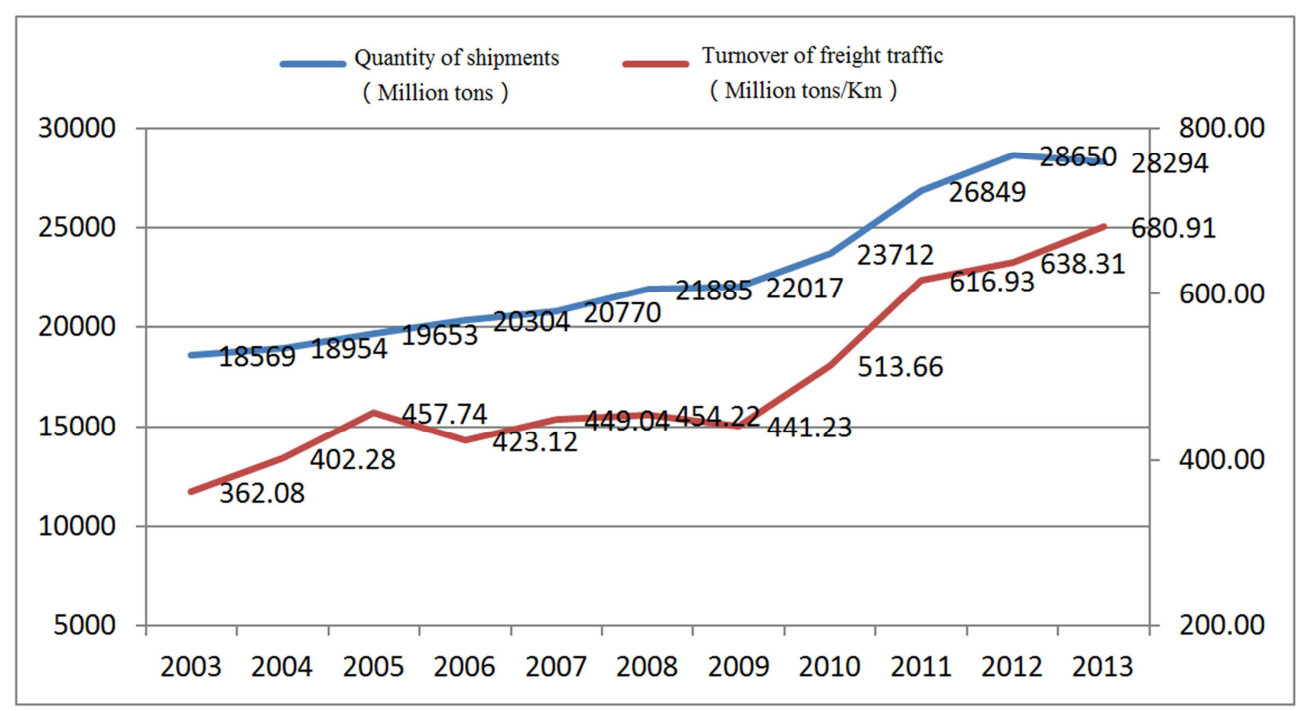

Figure 3-1. 2003-2013 freight volume and freight turnover.

As can be seen from Figure 3-1, 2003-2013 Beijing freight traffic continues to grow, freight volume of 185.69 million tons in 2007, freight volume of 282.94 million tons in 2013, 2010 and 2010, growth is most obvious. Beijing freight turnover growth, maintain volatility from 36.208 billion ton-km growth in 2007 to $\$ 2013$ by 68.091 billion ton-km, jumped in 2010 and 2011, that Beijing logistics demand appeared jumped over the past two years, the logistics demand is rapidly expanding. 


\subsection{Analyses of Variation Characteristics of Beijing Logistics Demand of Transportation Structure}

Transportation refers to the transport of the total share of freight volume, complete the various modes of transport ratio. As shown in table 3-1,3-2.

Table 3-1. 2007-2013 different transportation freight volume ratio.

\begin{tabular}{lllll}
\hline & Railway & Road & Civil Aviation & Pipe \\
\hline 2007 & $9.27 \%$ & $86.05 \%$ & $0.47 \%$ & $4.21 \%$ \\
2008 & $7.92 \%$ & $85.40 \%$ & $0.42 \%$ & $6.26 \%$ \\
2009 & $7.43 \%$ & $85.18 \%$ & $0.44 \%$ & $6.95 \%$ \\
2010 & $6.63 \%$ & $85.12 \%$ & $0.55 \%$ & $7.71 \%$ \\
2011 & $5.14 \%$ & $86.69 \%$ & $0.49 \%$ & $7.68 \%$ \\
2012 & $4.30 \%$ & $87.00 \%$ & $0.47 \%$ & $8.23 \%$ \\
2013 & $3.81 \%$ & $87.12 \%$ & $0.48 \%$ & $8.58 \%$ \\
\hline
\end{tabular}

Table 3-2. 2007-2013 different transportation freight turnover ratio.

\begin{tabular}{lllll}
\hline & Railway & Road & Civil Aviation & Pipe \\
\hline 2007 & $59.79 \%$ & $17.66 \%$ & $8.38 \%$ & $14.18 \%$ \\
2008 & $55.82 \%$ & $18.51 \%$ & $7.85 \%$ & $17.82 \%$ \\
2009 & $51.99 \%$ & $19.92 \%$ & $8.05 \%$ & $20.04 \%$ \\
2010 & $50.12 \%$ & $19.78 \%$ & $9.39 \%$ & $20.71 \%$ \\
2011 & $50.46 \%$ & $21.45 \%$ & $7.70 \%$ & $20.39 \%$ \\
2012 & $48.19 \%$ & $21.90 \%$ & $7.67 \%$ & $22.24 \%$ \\
2013 & $47.46 \%$ & $22.94 \%$ & $7.22 \%$ & $22.37 \%$ \\
\hline
\end{tabular}

From the table in the 3-1 data can be seen, the freight volume of Beijing occupies a leading position in the freight volume in road transport, is the most important mode of transport, in 2013 the share rate of $87.12 \%$. Sharing rate declining from $9.27 \%$ in 2007 to $3.81 \%$ in 2013 , the railway freight volume, freight pipeline accounted for the proportion of the overall upward trend, $20074.21 \%, 2013$ reached $8.58 \%$, freight aviation share ratio remained essentially unchanged, the proportion is very small. Railway freight volume while increasing, but its in the transport of cargo status in the gradually shrinking,

This is dependent on the railway transportation enterprise gradually moved out of Beijing heavy industry, pipe logistics demand overall in the enhancement, is becoming more and more high, this is natural gas and gas energy demand more relevant.

It can be seen from Table 3-2, 2007-2013 railway transport has been the highest freight turnover, but accounted for the proportion of railway freight turnover decreased significantly, down from nearly $59.79 \%$ in 2007 to $47.46 \%$ in 2013 , the total freight volume of highway transportation and pipeline transportation proportion showed a steady upward trend, in 2013 has reached $22 \%$ the above reasons, freight turnover share rate changes with the change of the share rate of freight volume.

\subsection{The Forecast of Logistics Transportation Structure of Beijing Based on Grey Prediction Model}

This section separately predict freight share rate of each mode of transportation, and combines the result of cargo volume forecast in the previous chapter to get the freight of all kinds of transport mode. From table 3-1, 3-2 know all kinds of transport mode, all is not linear, the change of the share rate of not rise or decline monotonically process, due to changes in statistics and traffic volume, to practical samples after 2007, sample size is small,

So using grey prediction theory.

The grey system theory can be through a number of surface clutter, random parameters to find the inherent law of development of things and prediction, predicted by the limited information on the development of prediction of things, things will be gray level decreases, the required sample size is small, compared with the uncertainty and complexity of different modes of transport capacity sharing rate change, this chapter using GM $(1,1)$ of varioustransport modes in the next five years sharing rate forecast. Its principle is as follows:

Assume $\mathrm{x}^{(0)}=\left(x^{(0)}(1), x^{(0)}(2), \ldots, x^{(0)}(n)\right)$ is the original data series,

The 1-AGO sequence is $\mathrm{x}^{(1)}=\left(x^{(1)}(1), x^{(1)}(2), \ldots, x^{(1)}(n)\right)$, where

$$
x^{(1)}(k)=\sum_{i=1}^{k} x^{(0)}(i), \mathrm{k}=1,2, \ldots, \mathrm{n}
$$

The original series accumulated generating, influence of bad data in theoriginal series will be weakened, with the law of exponential growth, sequence satisfies a linear differential equation of order

$$
\frac{d x^{(1)}(t)}{d t}+a x^{(1)} t=b
$$

Marking parameter $A=(a, b)^{T}$, Where a is the development coefficient,

B called for the amount of ash, According to the least square algorithm $A=\left(B^{T} B\right)^{-1} B^{T} Y$, where

$$
B=\left[\begin{array}{cc}
-\frac{1}{2}\left(x^{(1)}(1)+x^{(1)}(2)\right) & 1 \\
-\frac{1}{2}\left(x^{(1)}(2)+x^{(1)}(3)\right) & 1 \\
\vdots & \vdots \\
-\frac{1}{2}\left(x^{(1)}(n-1)+x^{(1)}(n)\right) & 1
\end{array}\right] Y=\left[\begin{array}{c}
x^{(0)}(2) \\
x^{(0)}(3) \\
\vdots \\
x^{(0)}(n)
\end{array}\right]
$$

a, b put in (4.1), assuming $x^{(1)}(1)=x^{(0)}(1)$, so

$$
x^{(1)}(t)=\left(x^{(0)}(1)-\frac{b}{a}\right) e^{-a(t-1)}+\frac{b}{a}
$$

So the prediction value is,

$$
\begin{gathered}
x^{(1)}(k+1)=\left(x^{(0)}(1)-\frac{b}{a}\right) e^{-a k}+\frac{b}{a} \\
x^{(0)}(k+1)=x^{(1)}(k+1)-x^{(1)}(k)
\end{gathered}
$$

To test the accuracy of the model, 
The relative error:

$$
g(k)=\frac{x^{(0)}(k)-\hat{x}^{(0)}(k)}{x^{(0)}(k)} \times 100 \%
$$

Precision

$$
p=\left(1-\frac{1}{n-1} \sum_{k=2}^{n}|g(k)|\right) \times 100 \%
$$

P $>95 \%$ commonly, Model for the optimal.

The process of grey model are summarized as follows:

Step one: the original grey accumulated generating process of;

$$
\begin{gathered}
x^{(1)}(k+1)=(9.27 \%-0.685183018) e^{-0.150444323 k}+0.685183018 \\
x^{(0)}(k+1)=x^{(1)}(k+1)-x^{(1)}(k)
\end{gathered}
$$

The resulting model test as shown in table 3-3:

Table 3-3. Railway freight volume ratio of model test results.

\begin{tabular}{lll|l}
\hline & The actual value & The estimated value & The precision \\
\hline 2007 & $9.27 \%$ & $9.27 \%$ & \\
2008 & $7.92 \%$ & $8.28 \%$ & \\
2009 & $7.43 \%$ & $7.12 \%$ & $98.58 \%$ \\
2010 & $6.63 \%$ & $6.13 \%$ & \\
2011 & $5.14 \%$ & $5.27 \%$ & \\
2012 & $4.30 \%$ & $4.53 \%$ & \\
2013 & $3.81 \%$ & $3.90 \%$ & \\
\hline
\end{tabular}

The precision is very high, so this is a qualified model.

The highway freight volume forecasting of share rate, share rate calculation by the model parameters for highway freight volume:

$\mathrm{a}=-0.005211375, \mathrm{~b}=0.8429713, \operatorname{input}(3.4)$ :

\begin{tabular}{|c|c|c|c|}
\hline & The actual value & The estimated value & The precision \\
\hline 2007 & $86.05 \%$ & $86.05 \%$ & \\
\hline 2008 & $85.40 \%$ & $84.97 \%$ & \\
\hline 2009 & $85.18 \%$ & $85.41 \%$ & \\
\hline 2010 & $85.12 \%$ & $85.86 \%$ & $99.81 \%$ \\
\hline 2011 & $86.69 \%$ & $86.31 \%$ & \\
\hline 2012 & $87.00 \%$ & $86.76 \%$ & \\
\hline 2013 & $87.12 \%$ & $87.21 \%$ & \\
\hline
\end{tabular}

$$
\begin{gathered}
x^{(1)}(k+1)=(86.05 \%+161.7560155) e^{0.005211375 k}-161.7560155 \\
x^{(0)}(k+1)=x^{(1)}(k+1)-x^{(1)}(k)
\end{gathered}
$$

The resulting model test as shown in table 3-4:

Table 3-4. Highway freight volume ratio of model test results

The precision is very high, so this is a qualified model.

For the civil aviation freight volume forecast by share rate, share rate calculation model parameters for civil aviation freight volume:

$a=-0.01645774, b=0.004448853$, input (3.4):

$$
x^{(1)}(k+1)=(0.47 \%+0.270319814) e^{0.01645774 k}-0.270319814
$$




$$
x^{(0)}(k+1)=x^{(1)}(k+1)-x^{(1)}(k)
$$

The resulting model test as shown in table 3-5:

Table 3-5. Civil aviation cargo sharing rate model test results.

\begin{tabular}{llll}
\hline & The actual value & The estimated value & The precision \\
\hline 2007 & $0.47 \%$ & $0.47 \%$ & \\
2008 & $0.42 \%$ & $0.46 \%$ & \\
2009 & $0.44 \%$ & $0.46 \%$ & $96.84 \%$ \\
2010 & $0.55 \%$ & $0.47 \%$ & \\
2011 & $0.49 \%$ & $0.48 \%$ & \\
2012 & $0.47 \%$ & $0.49 \%$ & \\
2013 & $0.48 \%$ & $0.50 \%$ & \\
\hline
\end{tabular}

The precision is very high, so this is a qualified model.

The pipeline freight volume forecast by share rate, share rate calculation model parameters for pipeline freight volume: $a=-0.05751944, b=0.060940684 \operatorname{input}(3.4)$ :

$$
\begin{gathered}
x^{(1)}(k+1)=(4.21 \%+1.059479794) e^{0.05751944 k}-1.059479794 \\
x^{(0)}(k+1)=x^{(1)}(k+1)-x^{(1)}(k)
\end{gathered}
$$

The resulting model test as shown in table 3-6;

Table 3-6. Pipeline cargo sharing rate model test results.

\begin{tabular}{lll|l}
\hline & The actual value & The estimated value & The precision \\
\hline 2007 & $4.21 \%$ & $4.21 \%$ & \\
2008 & $6.26 \%$ & $6.52 \%$ & \\
2009 & $6.95 \%$ & $6.91 \%$ & $98.29 \%$ \\
2010 & $7.71 \%$ & $7.32 \%$ & \\
2011 & $7.68 \%$ & $7.75 \%$ & \\
2012 & $8.23 \%$ & $8.21 \%$ & \\
2013 & $8.58 \%$ & $8.70 \%$ & \\
\hline
\end{tabular}

The precision is very high, so this is a qualified model.

\begin{tabular}{|c|c|c|c|c|}
\hline Years & Railway & The road & Civil Aviation & Pipe \\
\hline 2015 & $2.89 \%$ & $88.12 \%$ & $0.51 \%$ & $9.76 \%$ \\
\hline 2016 & $2.48 \%$ & $88.58 \%$ & $0.52 \%$ & $10.33 \%$ \\
\hline 2017 & $2.14 \%$ & $89.05 \%$ & $0.53 \%$ & $10.94 \%$ \\
\hline 2018 & $1.84 \%$ & $89.51 \%$ & $0.54 \%$ & $11.59 \%$ \\
\hline 2019 & $1.58 \%$ & $89.98 \%$ & $0.55 \%$ & $12.28 \%$ \\
\hline
\end{tabular}

In summary the 2015-2019 freight volume forecasting of share rate, the results are as shown in table 3-7:

Table 3-7. 2015-2019 freight volume share forecast value.

\begin{tabular}{|c|c|c|c|c|}
\hline Years & Railway & The road & Civil Aviation & Pipe \\
\hline 2015 & 901.47 & 27516.71 & 159.91 & 3046.20 \\
\hline 2016 & 807.50 & 28799.83 & 169.26 & 3359.46 \\
\hline 2017 & 722.20 & 30095.60 & 178.88 & 3699.13 \\
\hline 2018 & 644.97 & 31404.13 & 188.77 & 4067.25 \\
\hline 2019 & 575.23 & 32725.51 & 198.93 & 4465.99 \\
\hline
\end{tabular}

According to the Beijing freight transport mode in2015-2019 forecast freight volume value, as shown in table 3-8:

Table 3-8. 2015-2019 different transportation freight volume forecast.

From table 3-7 and 3-8 it can be seen that the railway freight volume, freight rate and share share rate showed a downward trend, logistics of railway transportation will continue to shrink in the next few years, the flow diversion by other modes of transport, such as various types of energy transport will gradually lose all by Guan Daoyun, the share rate of rise the trend of highway freight volume and freight volume of pipeline, freight volume is also rising, the amount of road transport logistics and transportation will continue to increase in the next few years, and the highway transportation because of its advantages of itself, will take other means of transport logistics quantity; in short, the next 
few years the amount of logistics in Beijing will be more and more large logistics demand will become more and more strong.

According to the data in Table 3-2, the freight turnover

$$
x^{(1)}(k+1)=(59.79 \%-19.01050963) e^{-0.030076675 k}+19.01050963 x^{(0)}(k+1)=x^{(1)}(k+1)-x^{(1)}(k)
$$

The resulting model test as shown in table 3-9:

Table 3-9. Railway freight turnover ratio of model test results.

\begin{tabular}{lll}
\hline & The actual value & The estimated value \\
\hline 2007 & $59.79 \%$ & $59.79 \%$ \\
2008 & $55.82 \%$ & $54.55 \%$ \\
2009 & $51.99 \%$ & $52.94 \%$ \\
2010 & $50.12 \%$ & $51.37 \%$ \\
2011 & $50.46 \%$ & $49.85 \%$ \\
2012 & $48.19 \%$ & $48.37 \%$ \\
2013 & $47.46 \%$ & $46.94 \%$ \\
\hline
\end{tabular}

The precision is very high, so this is a qualified model.

$\mathrm{a}=-0.040953142, \mathrm{~b}=0.175784513$ input $(3.4)$

On the highway freight volume forecast by share rate, share rate calculation model for highway freight volume:

$$
\begin{gathered}
x^{(1)}(k+1)=(17.66 \%+4.292332713) e^{0.040953142 k}-4.292332713 \\
x^{(0)}(k+1)=x^{(1)}(k+1)-x^{(1)}(k) \quad \text { The resulting model test as shown in table 3-10: }
\end{gathered}
$$

Table 3-10. The road freight turnover ratio of model test results.

\begin{tabular}{llll}
\hline & The actual value & The estimated value & The precision \\
\hline 2007 & $17.66 \%$ & $17.66 \%$ & \\
2008 & $18.51 \%$ & $18.68 \%$ & \\
2009 & $19.92 \%$ & $19.46 \%$ & $99.19 \%$ \\
2010 & $19.78 \%$ & $20.28 \%$ & \\
2011 & $21.45 \%$ & $21.12 \%$ & \\
2012 & $21.90 \%$ & $22.01 \%$ & \\
2013 & $22.94 \%$ & $22.93 \%$ & \\
\hline
\end{tabular}

The precision is very high, so this is a qualified model.

For the civil aviation freight turnover ratio was predicted by the model parameters, the share rate of aviation freight

$$
\begin{array}{rr}
x^{(1)}(k+1)=(8.38 \%-4.216921345) e^{-0.020526533 k}+4.216921345 \\
x^{(0)}(k+1)=x^{(1)}(k+1)-x^{(1)}(k) & \text { The resulting model test as }
\end{array}
$$

volume is calculated:

$\mathrm{a}=0.020526533, \mathrm{~b}=0.086558776 \operatorname{input}(3.4)$

Table 3-11. Aviation freight turnover ratio model test results.

\begin{tabular}{llll}
\hline & The actual value & The estimated value & The precision \\
\hline 2007 & $8.38 \%$ & $8.38 \%$ & $8.40 \%$ \\
2008 & $7.85 \%$ & $8.23 \%$ & $8.06 \%$ \\
2009 & $8.05 \%$ & $7.90 \%$ & $96.47 \%$ \\
2010 & $9.39 \%$ & $7.74 \%$ & $7.58 \%$ \\
2011 & $7.70 \%$ & $7.67 \%$ & \\
2012 & $7.22 \%$ & & \\
2013 & &
\end{tabular}

The precision is very high, so this is a qualified model.

The pipeline freight turnover ratio was predicted by the model parameters, the share rate of freight turnover for the calculation of pipe: $a=-0.039854289, b=0.176633931 \operatorname{input}(3.4)$ : 


$$
x^{(1)}(k+1)=(14.18 \%+4.431993016) e^{0.039854289 k}-4.431993016
$$

$$
x^{(0)}(k+1)=x^{(1)}(k+1)-x^{(1)}(k)
$$

The resulting model test as shown in table 3-12

Table 3-12. Pipeline freight turnover ratio model test results.

\begin{tabular}{lll|l}
\hline & The actual value & The estimated value & The precision \\
\hline 2007 & $14.18 \%$ & $14.18 \%$ & \\
2008 & $17.82 \%$ & $18.60 \%$ & \\
2009 & $20.04 \%$ & $19.35 \%$ & $99.25 \%$ \\
2010 & $20.71 \%$ & $20.14 \%$ & \\
2011 & $20.39 \%$ & $20.96 \%$ & \\
2012 & $22.24 \%$ & $21.81 \%$ & \\
\hline 2013 & $22.37 \%$ & $22.70 \%$ & \\
\hline
\end{tabular}

The precision is very high, so this is a qualified model.

In summary the 2015-2019 freight turnover share prediction rate, the results are as shown in table 3-13:

Table 3-13. 2015-2019 freight turnover share forecast value.

\begin{tabular}{lllll}
\hline Years & Railway & The road & Civil Aviation & Pipe \\
\hline 2015 & $44.20 \%$ & $24.88 \%$ & $7.27 \%$ & $24.58 \%$ \\
2016 & $42.89 \%$ & $25.92 \%$ & $7.13 \%$ & $25.58 \%$ \\
2017 & $41.62 \%$ & $27.01 \%$ & $6.98 \%$ & $26.62 \%$ \\
2018 & $40.38 \%$ & $28.14 \%$ & $6.84 \%$ & $27.70 \%$ \\
2019 & $39.19 \%$ & $29.31 \%$ & $6.70 \%$ & $28.83 \%$ \\
\hline
\end{tabular}

According to the Beijing freight results irrespective of the mode of transport in the prediction of 2015-2019cargo value, as shown in table 3-14:

Table 3-14. 2015-2019 different transportation freight volume forecast value.

\begin{tabular}{lllll}
\hline Years & Railway & The road & Civil Aviation & Pipe \\
\hline 2015 & 326.49 & 183.82 & 53.73 & 181.58 \\
2016 & 332.04 & 200.70 & 55.17 & 198.04 \\
2017 & 336.97 & 218.68 & 56.53 & 215.54 \\
2018 & 341.33 & 237.81 & 57.80 & 234.14 \\
2019 & 345.12 & 258.16 & 59.01 & 253.89 \\
\hline
\end{tabular}

From table 3-13 and 3-14 can be seen though the share of railway freight turnover rate decreased, but the total increase in the volume of goods, while the railway freight volume on the decline, indicating the displacement of foreign railway transportation will be more and more long railway because of its shortcomings, the traffic will be diverted to other modes of transportation; contribution rate rising road freight turnover and pipeline transport turnover, turnover is also rising, that a rapid increase in the flow of the next few years, highway transportation and pipeline transport, and road transport and pipeline transport due to its advantages, will take other means of transport logistics. In short, Beijing logistics demand in the next few years will be more and more strong, the logistics quantity will be more and more.

\section{Summary}

In recent years, with the continuous development of regional economy in Beijing, provides a good opportunity for the development of the logistics industry in Beijing. In order to make the logistics industry to maintain rapid development, lasting, the need for overall planning of logistics development, therefore, to carry on the forecast to the logistics demand, the paper analyzes the logistics demand forecast of Beijing, has made progress as follows:(1) analysis of the research background and research significance of logistics demand, summarizes the current situation of logistics demand in China, analyzed the present situation and development of environmental logistics development in Beijing. (2) through the analysis of economic impact of Beijing logistics demand, select the appropriate indicators to construct the index system of logistics demand forecast, using the econometric model to forecast the logistics demand of Beijing, the use of Eviews modeling and analysis of Beijing logistics demand, the rapid growth in the next five years the conclusion (3) using the grey prediction model to forecast the Beijing freight, freight turnover structure prediction, by calculating the freight volume in 2007-2013 years, the freight volume ratio, the establishment of GM $(1,1)$ model, the Beijing railway, highway, aviation and pipeline in the sharing rate is predicted from 2015 to 2019, according to the results of prediction total logistics needs, calculate all kinds of freight volume in the next five years, the freight volume. From the results, the highway freight transportation and pipeline transportation of freight turnover ratio gradually increased the gradual decline in the share rate of freight, railway freight turnover, the change of civil aviation freight volume and freight turnover is not. Various modes of transport capacity load increases and decreases, the transportation structure has changed greatly, but the total logistics needs in the rapid growth.

But due to the limited level of knowledge and cognition, there exist the following problems: (1) this paper only focus on economic factors of Beijing logistics demand, logistics demand is affected by other factors, the quantitative relationship between the factors and the logistics demand and the impact of some problems, may have overlooked some important explanatory variables; (2) only predict the freight, freight turnover on the macro level, the spatial distribution of logistics demand, flow and flow without considering. (3) in the theoretical study of the definition of the material flow is different, there is no statistical data on the logistics quantity of authoritative and credible, so the transport volume forecast logistics quantity, only that the general trend of the development of logistics demand.

\section{Acknowledgements}

This paper is funded by the project of National Natural 
Science Fund, Logistics distribution of artificial order picking random process model analysis and research(Project number: 71371033); and funded by intelligent logistics system Beijing Key Laboratory (No. BZ0211); and funded by scientific-research bases--Science \& Technology Innovation Platform---Modern logistics information and control technology research (Project number: PXM2015_014214_000001); and funded by 2014-2015 school year, Beijing Wuzi University, College students' scientific research and entrepreneurial action plan project (No.68); and funded by Beijing Wuzi University, Yunhe scholars program (00610303/007); and funded by Beijing Wuzi University, Management science and engineering Professional group of construction projects. (No. PXM2015_014214_000039). University Cultivation Fund Project of 2014-Research on Congestion Model and algorithm of picking system in distribution center (0541502703), and funded by Beijing philosophy and social sciences planning project "Statistical measure and quantitative studies on the development of green logistics in Beijing "(13JGC078).

\section{References}

[1] Cai Xiaoli,Analysis and forecast of regional logistics demand [J]; logistics technology, 2004 (12)

[2] Zhang Fengrong, Jin Junwu; the application of grey system model in the prediction of logistics amount of goods.[J]; 2003 (06) of industrial technology economy

[3] Cao Mingxia; Study on the grey incidence analysis model and its application [D]; Nanjing University of Aeronautics \& Astronautics 2007
[4] Chen Changying. Research on analysis and forecast of logistics demand in Guangxi [D]; Wuhan University of Technology 2010

[5] Zhang Lixue; Study on the prediction method of city logistics demand [D]; Southeast University; 2006

[6] Sun Minwei, Shao Jianli; Study on the establishment of a modern logistics system of statistical indicators [J]; 2007 (20) of modern business

[7] Gong Shusheng, Liu Kaiming; Analysis of the development situation of logistics in China [J] China circulation economy; $2003(01)$

[8] Chandyan; Wang Wenke; Hunan Province logistics demand forecast [A]; "two types of social construction and management of" HunanInnovation Forum [C] 2008

[9] Yang Fan; Analysis of the influence of Chinese modern logistics industry on regional economy [D]; Jilin University 2011

[10] Zhao Qilan; Wang Jia Qiong; Liu Hongzhi; analysis of the logistics development needs and potential demand;[J]; China soft science 2004

[11] Wang Xiaoyuan, Li Jun. The grey GM $(1,1)$ model is applied to Forecasting Regional Logistics Scale, Journal of Wuhan University of Technology, 2005 (06)

[12] Cai Dingping; logistics statistics [M] 2010.03

[13] Chen Yana, Ju Songdong; regional logistics demand analysis -- Taking the Yangtze River Delta region of Nantong as an example [J]; Journal of Beijing Jiaotong University (SOCIAL SCIENCE EDITION) 2005 (04)

[14] Cao Juan; the discussion on the construction of modern logistics system of statistical indicators of $[\mathrm{J}]$; logistics engineering and management, 2010 (1) 